DOI: $10.25100 /$ pfilosofica.v0i51.10119

\title{
FILOSOFÍA POLÍTICA EN EL PENSAMIENTO NEOCLÁSICO DE EUGENIO TRÍAS: UNA LECTURA DE EL ARTISTA Y LA CIUDAD
}

\section{José Daniel Parra \\ Universidad Externado de Colombia, Bogotá, Colombia.}

\begin{abstract}
Resumen
En El artista y la ciudad, el filósofo Eugenio Trías propone una recuperación ontológica de la relación entre eros y poiesis. Plantea esta aproximación como antídoto frente al desencantamiento del mundo que, a su juicio, se deriva del dualismo moderno que se manifiesta en la distinción mecánica entre producción y deseo. Para remediar el problema de la enajenación y la dispersión de la modernidad tardía, Trías retoma las figuras del artista $y$ la ciudad como puntos de referencia que encuentran resonancias paideicas en el símbolo renacentista de la academia platónica.
\end{abstract}

Palabras clave: filosofía política; eros; poiesis; artes liberales; paideia.

Cómo citar este artículo: Parra, J. D. (2020). Filosofía política en el pensamiento neoclásico de Eugenio Trías: Una lectura de El artista y la ciudad. Praxis Filosófica, (51), 55-76. doi: 10.25100/ pfilosofica.v0i51.10119

Recibido: 7 de enero de 2020. Aprobado: 13 de marzo de 2020. 


\title{
Political Philosophy in the Neoclassical Thought of Eugenio Trías: A Reading of The Artist and the City
}

\author{
José Daniel Parra
}

\begin{abstract}
In The Artist and the City philosopher Eugenio Trías offers an ontological recovery of the relation between eros and poiesis. Such approximation, in his view, provides an antidote to the disenchantment of the world derived from the modern dualistic mechanical disjunction between production and desire. In order to remedy the problem of alienation and dispersion in late modernity, Trias goes back to the figures of the artist and the city as reference points that find paideic resonances in the renaissance symbol of the platonic academy.
\end{abstract}

Keywords: Political Philosophy; Eros; Poiesis; Liberal Arts; Paideia.

${ }^{1}$ José Daniel Parra es doctor en filosofía política de la Universidad de Toronto. Actualmente es profesor e investigador en Gobierno y Relaciones Internacionales en la Universidad Externado de Colombia. Sus publicaciones abordan temas sobre historia del pensamiento político desde el mundo antiguo hasta la modernidad, teoría política, y terapia filosófica. Dirección Postal: Centro de Investigaciones y Proyectos Especiales (CIPE). Calle 12 No. 0 - 07 Este. Bogotá, Colombia.

ORCID: 0000-0001-6285-9855 E-mail: jose.parra@uexternado.edu.co 


\title{
FILOSOFÍA POLÍTICA EN EL PENSAMIENTO NEOCLÁSICO DE EUGENIO TRÍAS: UNA LECTURA DE EL ARTISTA Y LA CIUDAD
}

\author{
José Daniel Parra \\ Universidad Externado de Colombia, Bogotá, Colombia.
}

El artista y la ciudad plantea una aproximación triangular de fuentes intelectuales que han inspirado la obra del pensador barcelonés Eugenio Trías: la Grecia antigua, la Italia Renacentista, la Alemania de la filosofía del espíritu ${ }^{2}$. La apuesta del libro se centra en la conjunción de un eros "formativo y plasmador, capaz de objetivarse en el mundo cívico...[junto con una poiesis entendida como] creación productiva" (Trías, 1997, p. ii). De este modo busca una mediación entre eros y poiesis, y la correlación (no habla de identidad ni de analogía) entre polis y psique. El malestar que intenta diagnosticar y comenzar a curar culturalmente a través del texto es la enfermedad de la voluntad de la modernidad tardía: la aparente ruptura dualista, melancólica, entre visión filosófica y poder de acción.

El artista y la ciudad es un libro de corte clásico. Así, al parecer transmite una cierta frialdad. El texto propone un ejercicio exegético transversal: Trías actúa como lector de autores antiguos y su papel narrativo, podríamos decir, es todavía el de aprendiz que deja entrever un futuro ejercicio creador pero que aún no es directamente desplegado. El texto es, por tanto, una especie de Bildungsroman experimental, ensayístico, cuyo hilo conductor es rastrear

${ }^{2}$ Una serie de trabajos de Eugenio Trías que complementan y amplían el estudio de $E l$ Artista y la ciudad son: La Dispersión, Meditación sobre el Poder, Filosofía del Futuro, Filosofia y Carnaval, Ética y Condición Humana, Ciudad sobre Ciudad, El Hilo de la Verdad, Tratado de la Pasión y La Edad del Espíritu. Para un comentario sinóptico ver Pérez-Borbujo (2005). 
críticamente la historia del platonismo en la cultura europea. El autor comienza así a dar cuerpo a la noción de límite: encontrada en el idealismo alemán, en Kant, en Wittgenstein. En este libro Trías comienza a atreverse a "pensar la noción de límite en términos ontológicos" (Trías, 1997, p. iv).

Encontramos dos niveles de análisis a los que la obra intenta dar respuesta: el primero, ontológico en el sentido de la búsqueda de la estructura profunda del legado del platonismo europeo. A lo largo de su obra, Trías desarrolla este punto en términos de la distinción ontológica entre unidad y dispersión (Trías, 1997, p. 10). Segundo: un punto de vista político en el sentido de entrever formas del tiempo con facetas tanto clásicas como modernas. Esta perspectiva se desarrolla a su vez en tres ejes interrelacionados: a). el artista y la ciudad como analogía superior a la distinción cartesiana entre sujeto y objeto; b). la escisión moderna entre producción y deseo; c). el destino del hombre singular, encarnación de Proteo ${ }^{3}$.

El artista y la ciudad comprende una crítica a las ideologías modernas: parece comenzar con la idea regulativa de la utopía concreta. Este parece ser un sueño racional que constituye una alternativa respecto a la cooptación del pensamiento por parte de la ideología (Trías, 1997, p. 17). Pero esta aproximación es sólo tentativa ya que las nociones de "utopía concreta" y "sueño racional" se desarrollan en suelo moderno, que, por tanto, pareciera asumir una metafísica de la subjetividad basada en la distinción dualista entre sujeto y objeto. Trías propone una manera de aproximar armónicamente estos dos supuestos. De aquí se desprende su cuestionamiento al pensamiento heideggeriano: el filósofo barcelonés se acerca a Nietzsche para celebrar lo más próximo, la vida. Hace esta experimentación crítica ontológicamente: como condición de posibilidad de la fecundidad limítrofe, del eros poiético. Trías, sin embargo, toma de Heidegger la decisión de entrever este devenir desde la esfera de la Seinsgeschichte, en el sentido de su futura exploración de la historia del espíritu. De este modo busca arrojar luz sobre la posible relación entre teoría y práctica en el devenir de nuestro tiempo. Para ello echa mano de un modo de conocimiento que se produce en actos, y que de esta manera está en capacidad de proyectar un auténtico registro relacional histórico. Trías propone una crítica de la vita contemplativa desde una

${ }^{3}$ El inquieto Proteo llamado en la Odisea "anciano hombre de mar" (Homero, 1945, p. 133). Su nombre también traduce el "primero," el "primordial” o "primogénito." Podía predecir el futuro, y cambiaba de forma para evitar verse obligado a hacerlo, dando respuesta sólo a quien era capaz de asirlo o capturarlo. Una vez canaliza y comunica su mensaje, va de regreso al mar. Proteo tiene un carácter hermético, quizá por su relación con el océano en su sentido tanto trascendental como inconsciente. Se dice que la Orestíada de Esquilo culminaba con un cuarto acto, un drama satírico posiblemente titulado Proteo. 
reformulación de la praxis y la historia del espíritu en sentido platónicorenacentista (Trías, 1997, p. 18).

Este es un renacentismo limítrofe: no sólo ilustrado sino además pindárico ${ }^{4}$. Mantiene, según Trías, el imperativo vocacional ilustrado de cambiar el mundo, pero lo hace con una profunda consciencia según la cual el propósito y la manera de llevar a cabo esta tarea radica en responder a un llamado de retornar a ser quienes siempre hemos sido (Nietzsche, 2002b, $\S 270)^{5}$. En el pensamiento triasiano, como en Nietzsche, no habría dicotomía necesaria entre acción y contemplación. Esto se traduce en una apasionada búsqueda y afirmación de una tercera alternativa a partir de un despliegue histórico singular de la filosofía política platónica.

\section{Historia del Platonismo}

La filosofía platónica clásica, según Trías, insinúa una síntesis entre eros y poiesis. Trías parece reconocer oblicuamente la distinción clave entre Platón y platonismo. Por otro lado, encontramos en El artista y la ciudad un modelo interpretativo análogo al de Hans-Georg Gadamer en términos de la Wirkungsgeschichte. Estrictamente hablando no hay subjetividad en Platón, ni tampoco noción de síntesis en el sentido hegeliano moderno. Esto parece reconocerlo el texto: eros y poiesis "malamente pueden traducirse por deseo y producción" (Trías, 1997, p. 22). En el ámbito de la correlación entre interioridad y espacio público Trías se pregunta: ¿qué sucede cuando alma y ciudad dejan de ser órdenes interconexos y dialécticos para constituir esferas separadas y autónomas? ¿Cuándo el artista, en tanto que sujeto erótico y poiético pierde el punto de referencia de espacio, el hábitat que le es favorable, de la ciudad? Vemos el intento de asimilar el modelo platónico con el lenguaje cartesiano-kantiano de subjetividad y autonomía, pero tratando de mantener un tono clásico en términos de polis y psique. Se puede entrever una psicología política de corte platónico-nietzscheano tratando de emerger a lo largo del texto.

La pregunta, hermenéuticamente hablando, sería cómo reinterpretar la relación entre el hombre creador y sensible con respecto al plano de la ciudad. Para desarrollar este punto habría en primer lugar que tener en cuenta lo siguiente: el artista creador en sentido estricto no es una figura platónica. En la República Platón hace referencia al "artesano" que moldea un material dado según una función específica. Pero el artista, anota Trías, no orienta su

\footnotetext{
${ }^{4}$ Rickert (2002, p. 48) hace alusión a la relación entre la poesía pindárica y la fundación de la ciudad. Cf. Nietzsche (2003, § 211).

${ }^{5}$ Esta referencia desde el pensamiento de Nietzsche se aborda en Parra (2019, pp. 179, 190).
} 
trabajo en un área acotada y definida según el principio inexorable [en clave medieval] de la división del trabajo y de la especialización intransigente que parece suponer la kallipolis platónica.

Trías asemeja el artista a la figura de Proteo. Este personaje artístico, oceánico, multiforme que "muda constantemente de hacer, inclusive de ser, hasta el punto que puede definirse como un individuo que pretende ser y hacer todas las cosas" (Trías, 1997, p. 22). Es por este motivo, por ser alguien caleidoscópicamente constituido, que el Sócrates platónico sugiere que el artista debe ser retirado de la ciudad. En términos del libro X de la República, el problema está en caer en la imitación de la imitación: la idolatría que desafía o evade la aspiración hacia la virtud a causa de la afirmación y repetición compulsiva del consenso mimético. El falso poeta sería corruptor de la ciudad en la medida en la que pareciera ser fuente de una suerte de relativismo epistemológico, que deriva en un aparente relativismo ético, o en una mera asertividad consensuada del prejuicio tradicional irreflexivo.

El problema a un determinado nivel se sitúa en la disyuntiva entre ética (ethos) y estética (aisthesis). En Platón ambas están ligadas por la intuición noética, pero en la modernidad se separan, constituyendo esferas celosamente independientes - en Kant, por ejemplo, por medio de la distinción entre la razón práctica y el juicio estético. Esta distinción de decidido carácter moderno es ambivalente: separa las ideas de la belleza y el bien (por ejemplo, en Las Flores del Mal de Baudelaire). Se produce entonces un desfondamiento en dos niveles: a). un desfondamiento paideico donde el arte en apariencia deja de tener vocación filosófica para formar el carácter, $y, b)$. una desfiguración ontológica, en la medida en la que para Platón hay una íntima cercanía entre las ideas de la verdad, la belleza, y el bien. Al estar compartimentalizadas, podrían por tanto quedar en potencial contradicción. El arte moderno concibe una oportunidad en esa escisión de las ideas, así lo que se pierde en sustancia moral pareciera ganarse en dinamismo sensorial e interés estético. Como dice Nietzsche en el Crepúsculo de los Ídolos, leído desde un punto de vista decimonónico "Platón aburre" (Nietzsche, 2009). El desafío desde el pensamiento triasiano sería cómo aproximar de nuevo las ideas de la belleza, la verdad, y el bien, sin caer en moralismos en los que la paideia sea cooptada por el relativismo fragmentario o avasallada por un credo confesional de carácter absolutista.

\section{La ciudad renacentista: El retorno de Proteo}

Según el filósofo barcelonés, la estructura convencional del platonismo ha tradicionalmente desembocado en el problema del estatismo medieval: "cada individuo sometido al imperio de una sola actividad... sin que le sea posible 
bajo ningún concepto modificar esa fatalidad o condena" (Trías, 1997, pp. 22-23). Conforme a esta perspectiva, la estructura social sobre los artesanos banáusicos es salvaguardada por el filósofo-rey y su guardia pretoriana que le protege. Así habría una aparente asimilación de las esferas política y filosófica para supervisar y juzgar la base social productiva. La exclusión del artista ocurre, en principio, porque la existencia de éste no encaja dentro del orden jerárquico de filósofos, guerreros, y artesanos o labriegos.

Ahora bien: en su interpretación Trías da un giro más allá del medioevo cristiano para plantear una solución al dilema de la estructura vertical del modelo platónico-medieval: "sólo en una ciudad, no ideal como la platónica, sino real como la renacentista florentina, pudo pensarse la síntesis [entre eros y poiesis] en términos reales" ". Sin embargo, esta aproximación entre teoría y práctica pareciera ser oblicua. El artista proteico aparece reintegrado implícitamente en la ciudad renacentista. Al parecer, Trías no contempla la teoría a la manera aristotélica como necesidad y la práctica como un medio situado en la contingencia política para alcanzar una serie de fines públicos. Tampoco parece hacer referencia a la noción de phronesis, como lo hace Gadamer. Esta síntesis renacentista pareciera asumir una dialéctica hegeliana en lugar del dialegesthai socrático (cf. Apol., donde Sócrates prefiere hacer el papel de tábano para poder beneficiar a la ciudad, evitando así ser eliminado prematuramente por sus conciudadanos) ${ }^{7}$. Para Trías, como para el Nietzsche del Nacimiento de la Tragedia la figura socrática toma demasiada distancia del devenir de la polis: Sócrates es demasiado filósofo para la ciudadanía activa, y demasiado zetético para aventurar una ontología trascendental sistemática ${ }^{8}$.

A Trías en este texto no le interesa tanto el Sócrates mayéutico, sino que parece dar prioridad al Proteo artístico y poético. Es desde esta perspectiva que revisa la triple relación entre "eros y poiesis", "alma y ciudad", "arte y sociedad” (Trías, 1997, p. 24). El problema radica en que al desvincularse

6 "Ideal" no es una noción platónica. Hay que señalar que en El artista y la ciudad Trías se enfoca en el "platonismo," es decir, el legado histórico del pensamiento platónico. No plantea una aproximación socrática detallada y directa sobre los textos de Platón. Contrastar con Parra, 2009.

${ }^{7}$ En la Apología, Sócrates sostiene que el problema con los poetas es que dicen cosas líricamente muy bellas, pero sin dar cuenta de su significado o propósito. Los poetas clásicos tienden a caer en la soberbia, a causa de su pensamiento exaltado, a veces desbordadamente orgulloso. Por su parte, Nietzsche dirá que "no hay duda de que los poetas vienen del mar"; y añade: “qué te dijo Zaratustra aquel día? ¿Qué los poetas a menudo mienten? Pues Zaratustra es un poeta" también. Nietzsche (2002a, II). "Los Poetas."

${ }^{8}$ La manera de vida socrática está basada en formular preguntas para aclarar los motivos de acción de sus interlocutores, apoyado por analogías y mitos abiertos a la intuición noética. Ver Platón Fed. (100 a-b). (Hadot, 1993; Menn, 1995; Rosen, 1988; 1987, pp. 50-86). 
este triple juego de relaciones la esfera anímica pierde su correlato en la esfera social. De este modo eros aparentemente deja de encontrar en la idea de la belleza su principio y fundamento, perdiendo así el hilo conductor con la auténtica poiesis.

\section{Producción y Deseo}

Prácticamente hablando, el problema de fondo es el siguiente: el vínculo entre la producción y el deseo se encuentra escindido. Ha ocurrido una ruptura con la relación platónica entre poiesis y eros. La modernidad intenta una síntesis entre producción y deseo, pero el problema está en que ambas están basadas en una relación binaria (sujeto-objeto) y no triangular (ascenso erótico, vislumbre de la idea, descenso poiético). El artista y la ciudad explora esta triangulación por medio de la lectura de una selección de pasajes de los diálogos platónicos Fedro, Simposio, La República, y El Sofista. En esta selección se hace una revisión crítica de la filosofía en el sentido de aprender a morir. A nivel estructural, el pensamiento triasiano propone un estudio de estos diálogos para salir del problema de la razón ideológica, la cual es consecuencia política de la oclusión de la dimensión ontológica. El problema de la escisión entre la esfera del deseo y el ámbito de la producción es la cuestión de la anomía o la enajenación práctica que vivimos en la modernidad tardía. Una marcada discordia entre el "mundo anímico subjetivo del erotismo y el mundo cívico y objetivo del trabajo" (Trías, 1997, p. 22).

Trías encuentra una distinción clave entre el eros platónico y lo que la modernidad entiende como deseo. Un deseo no mediado, escindido de la producción, y que a su vez no considera necesaria la sublimación hacia la idea del bien o de la belleza. Un deseo, por otro lado, insaciable, pleonéxico, como consecuencia de la distancia abismal entre sujeto y objeto. El deseo hacia el objeto aparece como eternamente ausente y separado. Al no encontrar lugar de referencia ontológica fuera de sí mismo, el sujeto ahonda en una suerte de desesperación por falta de reencuentro con el objeto de su deseo más allá de su nuda subjetividad. Trías encuentra una correlación entre sujeto deseante escindido del objeto, y la noción de producción en su versión enajenada: actividad repetitiva, mecánica, carente de propósito vocacional - ajena por tanto de un fundamento o fuente superior. En la concepción autónoma de esferas separadas del deseo y de la producción, se da un quehacer ensimismado que busca la producción por la producción 
misma, y que tiene como posible consecuencia un desfondamiento subjetivo de carácter neurótico".

Trías va al Simposio de Platón para arrojar luz sobre esta disyuntiva. Interpreta allí a la figura de Diotima. Esto lo lleva a una descripción del camino ascendente del eros: "de los cuerpos bellos a las almas bellas, de las bellas virtudes a las bellas leyes, de estas a las bellas ciencias, hasta alcanzar finalmente la única ciencia, la ciencia de lo bello" (Platón, Simp. 210e). Y anota: si bien "la iniciación es gradual, la revelación es repentina, súbita". El fin (telos) del eros sería "la posesión de la belleza por parte del alma" (Trías, 1997, p. 29). Sin embargo, el propósito de la sublimación erótica es "menos simple" de lo que podría parecer (Trías, 1997, p. 30). Aquí entra la lectura trinitaria de Trías, quizá hasta cierto punto afín a la crítica agustiniana del platonismo dualista (Agustín de Hipona, 2002). El filósofo barcelonés critica la fría unidad o simplicidad del bien o lo bello, así como el problema de la excesiva abstracción atemporal (la "muerte") que así vista no se compadece de nuestra condición humana, y por tanto pareciera inhibir la capacidad de obrar voluntaria y apasionadamente en la dimensión del tiempo.

Desde la perspectiva triasiana la visión se experimenta como satisfacción que "apunta más allá de sí misma", y que por tanto deriva en una "acción o proceso ... de fecundación" (Trías, 1997, p. 31). Trías, por tanto, al parecer en línea con Nietzsche asocia misteriosamente a la verdad con la vida. El devenir de la verdad también se incorpora en la vida: vida entendida como el círculo eterno que va desde el ascenso erótico hasta la fecundación en lo bello, para devenir voluntaria y sustantivamente acto poiético. La auténtica verdad también es por tanto fecunda: da fruto al engendrar en lo bello.

Este enfoque parece dar vitalidad a una perspectiva genealógica en el pensamiento de Eugenio Trías ${ }^{10}$. El artista y la ciudad sostiene que lo que se

${ }^{9}$ Anota Thomas Mann: "el principio de la belleza y de la forma no procede de la esfera de la vida. Su relación con ella es, a lo sumo, de naturaleza altamente crítica y correctiva. Con orgullosa melancolía está enfrentada con la vida y, en lo profundo, está vinculada con la idea de la muerte y de la esterilidad" (citado en Trías, 1997, p. 27). Se experimenta que este extremo de fría lucidez melancólica puede ser aliviada por medio de un obrar que vincule el erotismo con la poiesis. Se alivia la melancolía inscribiendo, labrando signos, saliendo así del "dominio saturnal de un pensamiento perdido en ensueños taciturnos" (Trías, 1997, p. 120). Estos signos constituyen lo que Trías en un sentido amplio llama "poesía". Concluye: "ahora bien, en tanto media o remedia el quietismo taciturno la actividad creadora, en tanto la posesión deja paso a la escritura, al imperio del signo sensible, puede decirse entonces que el personaje se halla en vías de formación, de curación [...] comprende entonces que la aventura era aprendizaje". (Trías, 1997, p. 123).

${ }^{10}$ Martin Heidegger, en su estudio sobre Nietzsche, no menciona la genealogía como categoría fundamental. En este punto particular Trías está más cerca de Foucault y de Hannah 
ha de "engendrar son en primera instancia "bellos discursos y pensamientos, pero así mismo bellas normas y bellas leyes, bellos hijos, bellas ciudades, bellos saberes" (Trías, 1997, p. 31). Plantea que el objeto de eros no es "la posesión de la belleza a través de la contemplación sino la generación [...] en la belleza". Trías asevera esta afirmación con el testimonio que Diotima le confía al joven Sócrates: "no es el amor, Sócrates, como tú crees, amor de la belleza... (sino) amor de la generación en la belleza" (Simp. 206e). Así las cosas, la acción productiva al parecer rebasa la "pura contemplación visual" (Trías, 1997, p. 32). Trías concluye entonces que humanamente hablando el objeto que busca la psique no es sólo la contemplación de lo bello. O cómo esa contemplación además "se amplía o se prolonga en un acto más íntimo y más completo, el cual da lugar a una producción: una nueva génesis. O para hablar platónicamente, una poiesis" (Trías, 1997, p. 34). La visión ontológica es el punto de encuentro o mediación triangular entre el ascenso erótico (filosófico-artístico) y el descenso poiético (en el sentido de génesis, fundación política, Herkunft histórico). La genealogía de eros parece convertirse así en una apasionada filosofía de la historia ${ }^{11}$.

Esta interpretación modernizante del Simposio da un paso más con respecto a la visión socrática del Fedón: allí el alma se descubre congenial a la idea, se contempla por tanto "no engendrada e imperecedera, no sujeta a movimiento, entonces el acto de visión, que es el que tiene el alma de más propio y esencial, constituye, así mismo, un punto de reposo y descanso eterno que bajo ningún concepto puede desencadenar en acción productiva alguna" (Trías, 1997, p. 32). Trías resuelve esta aparente contradicción interpretando al Fedón como un diálogo temprano dentro del corpus platonicum. La apasionada interpretación que hace Trías de Platón le imprime movimiento histórico a la experiencia ontológica. Según Trías, en el Simposio, como en la República, "coexisten" las doctrinas estáticas y dinámicas. Trías llama el Fedón "un texto primerizo," ya que "desconoce el momento teorético en un acto más pleno y más fecundo," cuyo lugar de apoyo vendría dado por la metáfora erótica (Trías, 1997, p. 34). Trías critica así "el estatismo de la doctrina del Fedón". La idea "también sufre, a partir de los diálogos Parménides, Sofista, y Fedro, un cambio de estatuto, evidenciado en la inclusión, dentro del inventario ideal, del movimiento, de la diferencia, del no-ser" (Trías, 1997, p. 37). Desde esta perspectiva eros, en asocio con la poiesis, se transforma en principio de vida, motor anímico.

Arendt (con su enfoque en la natalidad) que del enfoque sobre la finitud de Heidegger. (Heidegger, 2014, §46-53).

${ }^{11}$ Trías define poiesis como: "causa que hace que lo que no es llegue a ser." Cf. (Nietzsche, 2003, § 211). 
Del ánima o alma se empieza a dar el salto al ánimo o espíritu. No es claro, por tanto, si Trías distingue suficientemente entre eros y thumos.

Sea como fuere, según esta interpretación, "Platón superaría la versión de eros como mero deseo que por tanto tiene carencia en su persecución del objeto" (Trías, 1997, p. 35) ${ }^{12}$. Continúa: eros, además, no se halla satisfecho por la posesión de lo que le falta "belleza o bien. O esa satisfacción no se cumple con la simple contemplación" (Trías, 1997, p. 35). ¿Por qué? Porque desde una perspectiva triasiana el objeto de eros es la generación. Plantea así que Platón logra una integración unitaria y prolífica de eros y poiesis que la modernidad ha fragmentado. Al parecer, esto traduce en una afirmación de la naturaleza daemonica, medianera, de eros: "ni inmortal como los dioses, ni mortal como los hombres. En virtud de esa fertilidad consigue reproducirse eternamente" (Trías, 1997, p. 36). Trías intenta encontrar un equilibrio humano en esta interpretación metaxica: eros busca un "término medio entre el proceso errático de generación y corrupción propio del mundo sensible y el estado estático de la pura visión beatífica propia de los inmortales" (Trías, 1997, p. 37). Eros puede madurarse: la visión filosófica no es sólo una iluminatio, o no lo es únicamente. Lo que se desvela ante la visión es la idea. Idea se relaciona con visión, que además, según Trías, "tiene la misma raíz - vid - de la que deriva la también griega palabra teoría o la latina videre" (Trías, 1997, p. 37) ${ }^{13}$. Parece así haber una correlación entre ascendencia y fertilidad, decadencia y esterilidad. De este modo el arte decadente resulta de una suerte de "impulso orgiástico sin obra" (Trías, 1997, p. 39).

Aunque Nietzsche en El Origen de la Tragedia se desmarca de la teoría en clave platónico-socrática, Trías insiste en que por el contrario la filosofía de Nietzsche "brota esencialmente de ella" (Trías, 1997, p. 40). De tal modo que hay acuerdo hasta cierto punto con la tesis de Heidegger: Nietzsche también 'platoniza' (Nietzsche, 2003, Prefacio; §14, §28, §190). El artista y la ciudad aventura por tanto una asociación entre teoría y práctica, ser y devenir, razón y revelación, ontología y genealogía o (Génesis). El punto de encuentro entre Platón y Nietzsche se daría en el plano histórico con figuras como la de Marsilio Ficino y el modelo de la academia platónica

\footnotetext{
${ }^{12}$ Trías antepone aquí una doble crítica al psicoanálisis lacaniano: a). La deuda y vocación no desde Heidegger, sino desde Goethe: la fruición del todo por medio de sus partes. b). La relación de "alteridad inmediata" vinculante (platónica, y para Trías eventualmente hegeliana) entre sujeto (alma) y sociedad (ciudad).

${ }^{13}$ Vid simboliza también uva, jugo de uva, o el vino. Trías busca armonizar el repertorio lúcido, visual, figurativo del principio de individuación apolíneo con la perspectiva fértil, solidaria, y nutricia que se conjuga, revitaliza y recrea en la pasión dionisíaca (Hadot, 1993, pp. 101-141; Nietzsche, 2003, §295).
} 
florentina. Encontramos aquí una relación experimental entre vida filosófica y vita activa: porque la producción erótico-poiética alcanza su "objetivo" "sobre todo a través de la política" (Trías, 1997, p. 42). La motivación de esta actividad paideica sería entonces la unión de eros y poiesis que encuentre su culminación en actos de producción o creación del que se componen obras. Afirma el pensador barcelonés que se puede dar un descenso voluntario del impulso poiético al reino de las sombras de manera que implante en este mundo los paradigmas contemplados en la ascensión. El filósofo platónico podría entonces ser potencialmente refundador o reformador (político) a razón de la conjunción entre visión erótica y regeneración poiética.

Así las cosas, el filósofo-poeta parece entrar en contacto con el devenir político ${ }^{14}$. ¿Pero de qué modo, y con qué medios? El filósofo-artista requeriría una especie de techné que invoque y saque a la luz las fuerzas o virtudes que están ocultas en la naturaleza (physis). Podría decirse que desde una perspectiva triasiana el artista ejerce una función 'mayéutica' sobre la ciudad misma (Trías, 1997, p. 43). La lectura de Trías sobre Platón se sitúa de algún modo entre el Tito Livio de Maquiavelo y el Hölderlin de Heidegger: un poeta fundador que encuentra en la filosofía una hermenéutica para regenerar formas de vida enraizadas en la historia. Trías, sin embargo, se inclina por considerar un mayor énfasis hacia la idea de la belleza ya que poiesis, en tanto que poesía, viene de lo alto, arrojando luz desde "más allá del ser" (epekeina tes ousías), hasta el no-ser (Trías, 1997, p. 47).

\section{El Artista en Exilio}

Al parecer en el Romanticismo se empieza a romper trágicamente la clásica estructura triangular erótico-poiética, produciendo la escisión entre sujeto y objeto: deseo subjetivo y producción maquinalmente objetiva. La manía divina platónica degenera en Todelust, "tentación del abismo,... [como] fin definitivo de todo amor" (Trías, 1997, p. 48). No hay en este nuevo escenario verdadera "apertura a la trascendencia, ya que el deseo no alcanza verdad, bien, o belleza sino muerte o locura, es decir, presencia de la 'verdad' como ausencia: "el alma pues, no encuentra lo que busca; por su parte, la ciudad, carece de fundamento sobre el cual edificarse" (Trías, 1997, p. 49). En ausencia del factor erótico-poiético la comunidad política se reproduce sin consideración abierta hacia el fundamento o fuente ontológica de verdad, bien común, y belleza. Como resultado de la producción por la producción

${ }^{14}$ Ver, sin embargo, Trías (1974, p. 138): "Hay que ser un gigante, como lo era Dostoievski, para conceder al hombre de acción el nombre que se merece: «un necio»." Contrastar con Hobbes (1994, p. 90) y Arendt (1992, p. 51). 
llegamos a una superproducción inmanente: movimiento enajenado sin tiempo para recordar la pregunta ontológica.

Trías considera que el problema habría que situarlo en el ámbito de la psicología política. Hay que ascender en el origen estructural de la experiencia singular no-escindida del pensador-poiético: evitando así que la poiesis caiga en una "productividad no mediada por belleza o calidad" (Trías, 1997, p. 50). Del mismo modo se busca que eros no degenere en mero amor-pasión sin apertura ontológica. Se evita así la desviación de un amor-pasión romántico subjetivista que tendría "en la locura o en la muerte su verdadera meta"15. El problema está en el doble contraste entre productividad enajenada (producir para producir, como supuesto principio de realidad, donde la maduración del impulso erótico no tiene cabida), $\mathrm{y}$, por otro lado, el deseo de muerte/locura, que al no tener mediación lúcida compartida se convierte en algo per-verso. En este punto del texto, Trías hace una recuperación clásica de la analogía entre alma y ciudad con el fin de abrir la mónada subjetiva ensimismada en el deseo narcisista: señala que "sólo a través de la producción y edificación cívica puede el sujeto salvar el bache emocional al que conduce necesariamente el deseo" (Trías, 1997, p. 50). El problema sin resolver en este punto del argumento es la forma de entender el símbolo o la idea de "ciudad" de tal manera que se pueda salvar a la filosofía poiética del activismo político.

Para recapitular: el filósofo barcelonés hace referencia a los diálogos Fedón (que considera "temprano" porque allí hay una fijación con la noción de "aprender a morir"), y por otro lado los diálogos eróticos Republica, Simposio, y Fedro donde hay una relación articulada entre eros y poiesis. Esta relación se ve truncada en el pensamiento romántico, dando origen a las nociones de deseo subjetivo, y producción enajenada: ambas separadas del ámbito trascendental de la idea de la belleza, entendida como afín a las ideas de la verdad y del bien. Hay por tanto un movimiento ascendente de eros que encuentra en la belleza un punto de equilibro armónico, a partir del cual, podría llevar a cabo una tarea de carácter paideico que despliegue y fecunde ese movimiento más allá del solipsismo subjetivo. Ahora bien: aunque las interpretaciones varían en amplia medida, Trías no resalta que en Platón propiamente pareciera no darse del todo el paso concreto hacia el gobierno de la ciudad. La imagen de la kallipolis o la "ciudad en el discurso" en la República, por ejemplo, es en primera instancia una magnificación del alma, diseñada o narrada por Sócrates para dialogar con sus jóvenes

${ }^{15}$ El Romanticismo narra el vínculo absoluto, no mediado de la muerte y el "extrañamiento del sujeto con el mundo objetivo.” Por ejemplo, en Werther de Goethe. (Trías, 1997, pp. 114-116). 
interlocutores sobre el problema de la justicia, el autoconocimiento, y la vida examinada. Trías, sin embargo, cita los casos de la ciudad florentina, la obra de Pico de la Mirandolla y de Marsilio Ficino para quizá entrever una relación de "utopía concreta" entre eros y poiesis en el plano histórico.

\section{Ciudades Platónicas}

Trías nos recuerda la premisa de la fundación de la ciudad en el discurso de la República: la ciudad surge por la falta de autosuficiencia de los hombres. La ciudad platónica, a diferencia del estado natural agustiniano-hobbesiano está fundamentada a partir del principio de la división del trabajo, basada en diferencias innatas: "no hay dos personas iguales por naturaleza" (Rep. 370 $a-b)$. Las diferencias naturales significativas son la premisa de la división del trabajo: cada cual debe atender una sola cosa, aquella para la cual está mejor dotado (Rep. 433 a). La justicia aquí consiste en dar a cada cual lo que cada cual merece. El hombre virtuoso según este modelo es un "ser simple, incapaz de abandonar la figura que le es propia" (Trías, 1997, p. 58). Incorpora la idea, basada en "simplicidad, inmutabilidad, identidad consigo misma, eternidad, fijeza, autosuficiencia" ${ }^{16}$. El problema desde la teoría política estaría en estimar si para recuperar a Platón es necesario también dar visto bueno a una rígida superestructura de gobierno "sostenida por 'perros guardianes' [...] y coronada por la figura egregia del filósofo-rey o del tirano-filósofo" (Trías, 1997, p. 55).

Para buscar solución a este dilema, el pensador barcelonés experimenta de nuevo con la figura del inquieto hombre proteico. Considera un posible desafío al anquilosamiento potencial del platonismo arquitectónico: "si algo repugna a esa visión platónica de la ciudad es la figura proteica de un individuo que encarna múltiples actividades y oficios” (Trías, 1997, p. 57). Pero el artista que intenta rescatar no es un mero rapsoda nomádico, sino que es a su vez pensador erótico. Trías encuentra en el uomo singulare renacentista un modelo ejemplar de ese carácter de vida.

En ese sentido, según Trías el Sofista sería un "diálogo avanzado" donde las categorías de "mismidad, reposo, ser" coexisten con sus opuestos “diferencia, movimiento, no-ser" (Trías, 1997, p. 59). La fijeza de la división

\footnotetext{
${ }^{16}$ En este contexto, Trías ofrece la siguiente tabla comparativa de la filosofía platónica y su "sombra":

Filosofía Platónica

Divinidad Simple

Idea Inmutable

Ser - Reposo - Mismo

Filósofo-rey

Orden Social (República \& Leyes)

\author{
Sombra \\ Proteo, Tetis \\ Eidola \\ No Ser - Movimiento - Otro \\ Artista Imitativo (Sofista) \\ ¿?
}


del trabajo la subvierten figuras como Proteo o Tetis: al parecer, figuras trágicamente afines no a la idea sino a la eidola. Nota, sin embargo, que "esa figura debe ser expulsada del panteón, ya que no permite estructurar la división del trabajo en términos de identidad entre "actividad y oficio" (Trías, 1997, p. 59). Al parecer, Proteo se asemeja no a la figura del artesano platónico que imita en el mundo la idea, manifestando la buena mimesis, sino a la del artista imitativo que produce simulacros: artista histriónico que realiza la mimesis a través de la simulación. Trías, sin embargo, propone una tercera figura entre el "buen artesano" y el "artista histriónico": la del artista creador. Amplía por tanto la referencia al modelo de la idea, dándole a su vez una dimensión física o cívica, evitando así el narcisismo histriónico, porque en vez de producir mera fantasía esta poiesis produciría "cosas" 17 (Trías, 1997, p. 59).

De este modo, se produce una crítica nominal cualificada a la kallipolis platónica. La interpretación triasiana nos hace entrever una ciudad donde cada sujeto es siempre otro que sí-mismo, donde el alma "es ella misma y también su diferencia". Una ciudad renacentista de vanguardia o limitrofe donde hombres y cosas son "todas las cosas" (Trías, 1997, p. 60). Pareciera haber un ensayo de aproximación desde la visión epistémica hacia la sensibilidad artística para entrever una solución al problema de la enajenación moderna. Sin embargo, el problema desde el punto de vista platónico al parecer reside en que "el artista y el poeta imitativo inspiran su actividad en unos principios que son antagónicos a los del filósofo y gobernante, ya que socaban un orden social fundado en el principio de identidad y en la división del trabajo" (Trías, 1997, p. 61). En términos prácticos, el artista polifacético presenta un problema en la estructura platónica, ya que cada uno puede practicar bien un solo oficio, pero no muchos.

Esta separación de papeles, sin embargo, "queda cuestionada" a partir de los diálogos Fedro, Parménides, y Sofista. Trías despliega a partir de Platón un desarrollo similar al de la filosofía occidental: desde la aurora de la identidad holística hasta el crepúsculo en la diferencia singular. El Sofista busca un punto de contacto y mediación entre los "amigos de la forma" y los "amigos de la materia." Esto al parecer concedería a la eidola un "cierto estatuto ontológico": Trías llega al postulado (no agustiniano) de que el no-ser en algún sentido también "es" (Trías, 1997, p. 62). Desde la lectura triasiana, en el Sofista se difumina la diferencia entre filósofo y artista imitativo (Trías, 1997, p. 63). Ahora bien, Trías también es consciente de que "el sofista y el artista imitativo se refugian constantemente en la eidola" (Trías, 1997, p. 63)

17 “Cosas" o Dingen en el sentido que le da Heidegger, en contraste con la Ding an Sich de Kant. Heidegger, 2001, pp. 163-184. 
y esto tiende a exacerbar el problema demasiado humano de la dispersión sensorial. La perspectiva del sofista pareciera estar en permanente cambio: carece de estabilidad epistémica, está psicológicamente dividido, lo que conlleva a una identidad inconstante; por tanto, pareciera no ser digno de confianza debido a su estado de fragmentación interior. Trías, sin embargo, propone que esta representación de cambio por parte del sofista parece no ser inconsistente con la perspectiva del alma en perpetuo movimiento del Fedro y de las Leyes (Libro X), y que hace posiblemente eco en la psique descrita en el Timeo con su "aleación entre mismo y otro" (Trías, 1997, p. 63). ¿Cómo estimar esta noción del alma en movimiento y su correlato político en las ciudades de la República y las Leyes? ¿Cuál es entonces el estatus epistemológico y ontológico del sofista? Como anotábamos, una posibilidad sería que la kallipolis de la República fuera sólo "ciudad en el discurso" y no un proyecto político. La ciudad de las Leyes por otro lado sería más "aristotélica", más situada teóricamente en la facticidad política. El sofista se distingue del filósofo socrático en que claramente cree poder diferenciar entre nomos y physis, lo cual le ofrece un parámetro crítico "natural" universal, mientras que el filó-sofo se sitúa dentro de la ciudad de una manera dialéctica, menos retóricamente contestataria, y más abierta al lento y sosegado proceso de explorar dialogadamente la vida examinada.

Trías, por su parte, insiste en que el Sofista ofrece un complemento hermenéutico a la República. De este modo busca integrar en el legado platónico el arte imitativo, como arte poiética, "del que también forma parte la agricultura", y así mismo "todas las artes que cuidan de un cuerpo mortal" (Sofista, 219 a-b). La pregunta sería entonces: por medio de qué arte cultivar una auténtica filosofía política platónica. Ante la oposición entre el filósofo escolástico y el artista mimético, Trías comprende que el filósofo dialéctico ofrece una alternativa. Sin embargo, quiere a su vez proponer una figura correspondiente en el terreno del arte. Ya que a su juicio, esa falta es delatora de una insuficiencia del planteamiento platónico. En términos de sociología del conocimiento se plantea entonces la siguiente pregunta: $¿$ es el filósofo dialéctico parte de la base social o de la superestructura gobernante y está por ello "sustraído del proceso de producción, a diferencia en esto del artista y del poeta, del agricultor, del médico y del artesano?" (Trías, 1997, p. 66). ¿En qué estamento sociopolítico se puede ubicar al filósofo dialéctico?

Al filósofo platónico-aristotélico "le cabe en la cabeza" toda la ciudad, ya que conoce sus límites. Entre tanto, "el artista produce ... en todas las direcciones hasta el punto que parece ser "todas las cosas." (cf. Sofista, $233 \mathrm{~d}$-e). A la claridad meditativa y dialéctica del filósofo se contrasta la aparente actividad febril del artista mimético quien, como el sofista, está 
especializado en la creación de simulacros. Trías anota provocadoramente: el artista histriónico, a diferencia del artista creador, no transforma el mundo: se limita a simularlo así como el filósofo-rey se limita a interpretarlo o contemplarlo. El filósofo contemplativo "no hace todas las cosas, tan sólo las sabe y las conceptúa; no siente y vive con las cosas, tan sólo las reflexiona, las registra mentalmente. Las conoce, pero nunca puede darlas a luz. Le falta, pues, ese momento del engendrar [...] que haría productiva su actividad" (Trías, 1997, p. 69). Por otro lado, el filósofo dialéctico: "piensa la unidad de lo diverso, pero piensa también la diferencia de lo idéntico" (Trías, 1997, p. 67). Este filósofo resulta más sutil que el filósofo dogmático que ignora la diferencia y el no-ser.

En última instancia, Trías un poco a la manera del Nietzsche del Nacimiento de la Tragedia, encuentra que el filósofo clásico se limita a pensar sin producir. Pero, se precisa que es justamente en virtud de ello que, en principio, puede mandar. El problema efectivamente no es sólo que pueda, sino que desee hacerlo. El filósofo socrático no desea sufrir las amarguras del poder político (cf. Apol., junto con la figura de Odiseo, en el Libro X de la República). En este contexto, para el pensador barcelonés faltaría una figura que incorpore del artista su disposición productora, así como su capacidad arquitectónica de realización: reconfigurando de esta manera la figura del filósofo abstraído del proceso productivo. A esta figura, según Trías, puede llamársele artista creador.

Este llamado al auténtico artista creador busca corregir la rígida división del trabajo de la República y de las Leyes. Busca dar paso a un modelo más dinámico, más moderno de movilidad vocacional. Es aquí donde Trías al parecer toma partido por la dialéctica del espíritu sobre el elenchus Socrático. La solución al "drama platónico" se daría entonces en un despliegue en el tiempo en una especie de filosofía de la historia ontológicamente concebida. Ahora bien: ni en Platón ni en Hegel el primado de la idea en ningún lado es cuestionado ni discutido. En medio de los dos referentes de Platón y Hegel, del mundo clásico y el mundo moderno, El artista y la ciudad sugiere por contraste una aproximación renacentista que podría encontrar mediación paideica en el redescubrimiento de la academia platónica ${ }^{18}$.

${ }^{18}$ Cf. La carta de Nietzsche a Erwin Rohde, diciembre 1870 (citada en Trías, 1997, p. $184 ; 2014$, p. 828). El tema de la refundación de la academia platónica en clave nietzscheana se explora en Parra (2013). Ver el trabajo clásico de Robin, 1908. 


\section{Conclusiones: Refundando la academia platónica o preludio a la filosofía del futuro}

Una reconsideración del modelo renacentista de la academia platónica podría iniciar con el estudio de tres figuras clave: Gemisto Pletón, Marsilio Ficino, y Pico de la Mirandolla. El artista y la ciudad ahonda en la figura de Pico, en especial su Oración sobre la Dignidad del Hombre.

Hasta cierto punto, Pico parece mantener la cosmovisión medieval de la "estratificación jerarquizada de regiones del ser" (Trías, 1997, p. 75). Este es un "cosmos cerrado" donde no habría un sujeto que interrogue la estructura de la "gran cadena del ser" en sentido de alteridad profunda. En este modelo arquitectónico se contempla que "todo tiene su lugar, todas las cosas se hayan definidas en su puesto natural: [...] "Dios, las mentes angélicas, el alma cósmica, el mundo sublunar, la materia" (Trías, 1997, p. 76). Encontramos escenificado un neoplatonismo donde el divinus influxus provee de energía espiritual todas las cosas. Este cosmos claustro, perfecto, carece de "ideas terribles como aquellas propias de la teología mística... que hablan de lo infinito" (Trías, 1997, p. 76). Trías llama la atención sobre el hecho de que el texto armónico y razonable de Pico no incluye el concepto moderno de universo. Ese cosmos evoca la estructura del platonismo medieval donde "cada cosa tiene su puesto, su rango en la jerarquía; todo se haya perfectamente ordenado y distribuido" (Trías, 1997, p. 77).

En este punto Trías se debate sobre quién es el hombre en el contexto de dicha estructura: "ni es dios, ni es bruto, ni es mente angélica, ni es alma cósmica, ni es materia" (Trías, 1997, p. 77). Pico de la Mirandolla ofrece una respuesta al acertijo de la identidad del hombre: "semejante a un gran camaleón, semejante a Proteo, el hombre precisamente porque no es ninguna cosa, puede ser todas las cosas" (cfr. Platón, Rep. 605b-c). Trías quiere añadir la experiencia de libertad - y por tanto la posibilidad del mal - al modelo platónico ${ }^{19}$. Nota que, en la recuperación renacentista, al carecer de lugar fijo, el hombre puede hacerse a un lugar: su esencia se encuentra cifrada en su libertad. En Pico "libre" significa que su identidad no está delimitada de antemano. Ser libre es su manera de existir. En la lectura triasiana la condición del hombre carece de naturaleza o de esencia. Por tanto, el hombre sería innatamente una suerte de artista poiético, ni celeste ni terreno: "puede ser lo que quiera, celeste y/o terreno, mortal y/o inmortal" (Trías, 1997, p. 78).

\footnotetext{
${ }^{19}$ Sobre la relación entre "libertad e infinito" ver el contraste entre Renacimiento y Barroco en Trías, 1988. El libro abre con una cita de Schelling: «Lo siniestro (Das Unheimliche) es aquello que, debiendo permanecer oculto, se ha revelado».
} 
Esta ambivalencia existencial arroja al hombre a forjar su destino, así como a recordar su misión y propósito. Al correr este riesgo el hombre "puede degenerar en las cosas inferiores que son los brutos, y también puede regenerarse en las superiores, que son las divinas" (Trías, 1997, p. 79). En la obra de Pico el hombre es interpretado como microcosmos: "no en el sentido de que sea el centro del cosmos. Es extraño con respecto al cosmos, excéntrico con respecto a la totalidad de las cosas" (Trías, 1997, p. 79). Trías encuentra que el hombre no es centro sino excentricidad: en quien el orden de la creación parece perder la cabeza. Anota: según qué cultive puede ser el hombre "una y otra cosa: si cultiva las vegetales, planta se hará; si las sensuales, bruto; si las racionales, ángel e hijo de Dios; y si no contento con la suerte de creatura alguna, se recogiera hacia el centro de su unidad, se hará espíritu uno con Dios" (Trías, 1997, p. 79). El hombre en tal sentido puede ser todas las cosas: puede "hacerse uno con Dios o dispersarse en la materia, llegar a "ser" o perderse en el "no-ser", recogerse en el "uno" o diluirse en "muchas cosas" (Trías, 1997, p. 80). Trías regresa al simbolismo del mundo pagano donde experimenta en clave musical (Trías, 2014) las metamorfosis del hombre a quien no es casual que en los misterios se le simbolizara con Proteo.

En otras palabras, Trías señala un "giro copernicano" por parte de Pico de la Mirandolla en la historia del platonismo. Los argumentos para expulsar al inquieto artista proteico son utilizados por Pico "como pruebas de admiración y maravilla" respecto al hombre "que basa su dignidad en eso mismo que para Platón [aparentemente] era iniquidad" (Trías, 1997, p. 80). Se genera una transfiguración si se quiere de la figura del artista: un retorno del exilio, a razón de un nuevo ajuste de la relación entre razón filosófica y vocación poiética. El artista poético "era expulsado por razón de sus metamorfosis, por razón de su incapacidad para asentarse en un lugar, para adecuarse a un oficio o actividad, para definirse según un patrón determinado de identidad. Ahora estas razones de expulsión son para Pico razones de incorporación" (Trías, 1997, p. 81).

Quizá el legado del platonismo llegó a ser demasiado exitoso hasta el medioevo tardío, de tal modo que Pico creyó necesario corregir el rumbo: la llegada del artista-pensador regenera el cuerpo social cerrado y juiciosamente conformado ya que introduce un principio de movilidad y energía. Mientras que la analogía del filósofo-rey sugiere que cada cual se mantenga en su sitio, el "artista coronado" desafía el estatismo piramidal. Para el pensador barcelonés esta es la figura del uomo universale y singulare: "el alma que es todas las cosas" quien a su vez es arquitecto o compositor de una forma 
de vida donde el hombre pudiera "encontrar algo así como una auténtica morada" (Trías, 1997, p. 81).

La plaza arquetípica de encuentro para integrar y experimentar diferenciadamente estas ideas es la academia platónica. Según Trías, la filosofía neoplatónica y la ciudad renacentistas interpretadas en sentido limítrofe pueden ser un criterio interior desde el cual estimar nuestro lugar en el curso de la historia con respecto a la analogía entre polis y psique. Trías considera oportuno en nuestro tiempo que esto se despliegue aventurando un diálogo entre Platón y Nietzsche: donde entren en juego la filosofía dialéctica y contemplativa, el desarrollo armónico, la poiesis artística, y una apertura a la maduración terapéutica de los afectos. En ese sentido fronterizo, la academia platónica, lugar de encuentro para las artes liberales, así como punto de fuga del desencantamiento actual, es alternativa para regenerar la paideia en nuestro tiempo.

\section{Referencias bibliográficas}

Arendt, H. (1992). Lectures on Kant's Political Philosophy. Edited with an

Interpretative Essay by Ronald Beiner. Chicago, EUA: University of Chicago Press.

Agustín de Hipona. (2002). The City of God against the Pagans. Cambridge, Inglaterra: Cambridge University Press.

Hadot, P. (1993). Exercices spirituels et philosophie antique. Paris, Francia: Albin Michel.

Heidegger, M. (2001). Poetry, Language Thought. New York, EUA: Harper \& Row. Heidegger, M. (2014). Ser y Tiempo. Buenos Aires, Argentina: Fondo de Cultura Económica.

Hobbes, T. (1994). Leviathan. Indianapolis, EUA: Hackett.

Homero. (1945). The Odyssey. Cambridge: Harvard University Press.

Menn, S. (1995). Plato on God as Nous. South Bend, EUA: St. Augustine Press.

Nietzsche, F. (2002a). Así habló Zaratustra. Madrid, España: Mestas.

Nietzsche, F. (2002b). La gaya ciencia. Madrid, España: Edaf.

Nietzsche, F. (2003). Más allá del bien y del mal. Madrid, España: Edimat.

Nietzsche, F. (2009). Crepúsculo de los ídolos. Valencia, España: Diálogo.

Parra, J. D. (2009). The Rhetoric of Action: A Reflection on Plato's Gorgias. Praxis Filosófica, (28), 55-75. doi: 10.25100/pfilosofica.v0i28.3274

Parra, J. D. (2013). Who Educates the Educators? Nietzsche's Philosophical Therapy in the Age of Nihilism. En H. Hutter y E. Friedland (Eds.), Nietzsche's Therapeutic Teaching (pp. 47-60). Londres, Inglaterra: Bloomsbury.

Parra, J. D. (2019). Heidegger's Nietzsche: European Modernity and the Philosophy of the Future. Lanham, EUA: Lexington Books.

Pérez-Borbujo, F. (2005). La otra orilla de la belleza: En Torno al Pensamiento de Eugenio Trías. Barcelona, España: Herder. 
Platón [Apol.]. (1997). Apology. En J. M. Cooper (Ed.), Complete Works (pp. 1736). Indianapolis, EUA: Hackett.

Platón [Fed.]. (1997). Phaedo. En J. M. Cooper (Ed.), Complete Works (pp. 49-100). Indianapolis, EUA: Hackett.

Platón [Rep.]. (1997). Republic. En J. M. Cooper (Ed.), Complete Works (pp. 9711223). Indianapolis, EUA: Hackett.

Platón [Simp.]. (1997). Symposium. En J. M. Cooper (Ed.), Complete Works (pp. 457-505). Indianapolis, EUA: Hackett.

Platón [Sofista]. (1997). Sophist. En J. M. Cooper (Ed.), Complete Works (pp. 235293). Indianapolis, EUA: Hackett.

Rickert, J. (2002). La Idea de ciudad: Antropología de la forma urbana en Roma, Italia, y el mundo antiguo. Prólogo de Eugenio Trías. Salamanca, España: Sígueme.

Robin, L. (1908). La Théorie Platonicienne des Idées et des Nombres d'après Aristote. Paris, Francia: Felix Alcan.

Rosen, S. (1988). The Quarrel Between Philosophy and Poetry. Nueva York, EUA: Routledge.

Rosen, S. (1987). Hermeneutics as Politics. New Haven, EUA: Yale University Press.

Trías, E. (1974). Drama e identidad. Barcelona, España: Barral Editores.

Trías, E. (1988). Lo bello y lo siniestro. Barcelona, España: Ariel.

Trías, E. (1997). El artista y la ciudad. Barcelona, España: Anagrama.

Trías, E. (2014). La edad del espiritu. Barcelona, España: Penguin. 
